\title{
Prevalence of HIV in a Tertiary Care Centre in Delhi: A Five-Year ICTC Based Study
}

\author{
Banke Lal Sherwal, Poonam Gupta, Rojalin Nayak, Sanjib Gogoi*, Sarika Suri, Renu Dutta \\ Department of Microbiology, Lady Hardinge Medical College, New Delhi, India \\ Email: drblsherwal703@gmail.com, drpoonamgupta@gmail.com, rojalinn@gmail.com, \\ drgogoisanjib24@gmail.com, drsarikamohan@gmail.com, drrenudutta@yahoo.co.in
}

Received 21 January 2015; accepted 9 February 2015; published 12 February 2015

Copyright @ 2015 by authors and Scientific Research Publishing Inc.

This work is licensed under the Creative Commons Attribution International License (CC BY). http://creativecommons.org/licenses/by/4.0/

(c) (i) Open Access

\begin{abstract}
Objective: The purpose of this study is to estimate the prevalence of HIV infection among the clients attending ICTC, LHMC of New Delhi, for a period of five years, i.e., from 2008 to 2012. Material \& Method: A total of 25,413 clients attended ICTC, LHMC from the year 2008 to 2012 . Serum samples were collected after taking informed consent and pre-test counseling. In India for all ICTCs, NACO (National AIDS Control Organization), a national guidelines has been followed for HIV testing, reporting and release of results with post test counseling. Results: Out of the total 25,413 clients tested for HIV infection, $963(3.78 \%)$ were found to be HIV-1 seropositive. Seropositivity was higher in male clients i.e. $625(64.4 \%)$ than female i.e. $336(34.8 \%)$ followed by transgender (TG), i.e., $2(0.2 \%)$. Heterosexual route of transmission was the major route seen in 676 clients (70.1\%). Maximum HIV seropositivity was in the age group of 25 - 34 years (35.4\%). No HIV-2 case was found among the studied population. Conclusion: HIV prevalence of $3.78 \%$ among the clients attending ICTC, LHMC, New Delhi, puts light on the burden on HIV in this part of the country and suggests the need for the scaling up of focused prevention efforts in high-risk groups.
\end{abstract}

\section{Keywords}

HIV, Seropositivity, ICTC, Heterosexual, Transgender

\section{Introduction}

Though India got the first case of HIV much later than in other parts of the world, in the present scenario HIV has emerged as a public health problem with enormous social and economic implications. The main risk behaviors and practices associated with a higher risk of HIV transmission in India include unprotected sexual inter-

\footnotetext{
${ }^{*}$ Corresponding author.
}

How to cite this paper: Sherwal, B.L., Gupta, P., Nayak, R., Gogoi, S., Suri, S. and Dutta, R. (2015) Prevalence of HIV in a Tertiary Care Centre in Delhi: A Five-Year ICTC Based Study. World Journal of AIDS, 5, 1-9. 
course, IV drug use, and transfusion of contaminated blood and blood products. Heterosexual route is the most common route of transmission in India which is associated with the factors like presence of untreated ulcerative sexually transmitted infections, irregular use of condoms, frequency of sexual contact, and age at sexual initiation. HIV is an infection which many people have fears, prejudices or negative attitudes about. Stigma can result in people with HIV being insulted, rejected, gossiped about and excluded from social activities [1].

A new hope has been seen recently in the AIDS epidemic with all the global efforts for the effective treatment and prevention programmes. Today India has launched NACP IV with its continuous commitment. There are approximately 34 million people currently living with HIV and about 30 million people have died of AIDSrelated causes since the beginning of the epidemic [2]-[4]. Latest data show that a 50\% reduction in the rate of new HIV infections (HIV incidence) has been achieved in 25 low and middle income countries between 2010 and 2011. India has a burden of 2.5 million people infected with HIV-1 making it the third largest HIV-1 epidemic in the world after Africa and Nigeria. The road from 2.5 million new HIV infections-the number in 2011 - to zero new HIV infection is a long one and there is a significant effort required to accelerate HIV prevention programmes [5]. India contributes to almost $60 \%$ of South Asia’s HIV epidemic [6].

In 1992, Government of India demonstrated its commitment to combat the disease with the launch of the first National AIDS Control Programme (NACP-I) as a comprehensive programme for prevention and control of HIV/AIDS in India [5]. Responding to the immense challenge of the HIV/AIDS threat in India, NACO has a response to increase access to services and effectively communicate for behavior change. With continuous efforts today we stand at the beginning of NACP IV. The concept of integrating the preventive and care services was indicated through the initiation of ICTCs in LHMC, New Delhi. The ICTC provides pre-test counseling, testing, post-test counseling and support services. Clients (including general population, high-risk groups excluding antenatal cases) utilize the services of the centre on voluntary basis.

\section{Aim}

This study was carried out retrospectively to estimate the prevalence of HIV infection in the clients attending ICTC at LHMC, New Delhi situated in North India.

The present study has documented the prevalence, risk factor of HIV infection and HIV-TB co-infection among the clients attending ICTC, LHMC (including general clients, HRGs excluding antenatal women).

\section{Material and Methods}

This is a retrospective study of clients who attended ICTC, LHMC, New Delhi of North India from January 2008 to January 2012. All the clients attending the ICTC were counseled and informed consent was taken from them by ICTC counselors. The data pertaining to the clients including name, age, sex, occupation, education, marital status, risk factor associated were documented in the register by ICTC counselors. All clients at ICTC were given unique PID number and he/she was directed for sample collection (3 - 5 ml of blood) at primary sample collection room at ICTC. Then HIV test was done in the HIV Laboratory, as per NACO guidelines with the 3 rapid test kits provided by DSACS/NACO [7].

The protocol of the rapid tests performed as per NACO guidelines [7] was as follows:

The first test kit was of highest sensitivity and the specificity increases with second and third kit. Therefore, when the test with first test kit is negative, second and third kit tests were not done and the result is negative for that tested sample. If the first test is positive, then second and third rapid kit tests were performed and if these two tests were also positive, then the final result was given as positive for that tested sample [7].

\section{Results}

In this study the prevalence of HIV was found to be 3.78\% (963/25413). Out of total 25,413 clients, 963 (3.78\%) tested positive for HIV-1. Maximum number of seropositivity was found in male clients (64.4\%), followed by $34.8 \%$ in female clients and $0.2 \%$ in transgender. No HIV-2 case was found among the population studied from the year 2008 to 2012 (Table 1).

The prevalence of seropositivity is depicted in Figure 1. A decreasing trend of seropositivity from 5.79\% in 2008 to 3.26\% in 2012 was observed over the period of study (Figure 1).

Maximum number of clients tested seropositive in the age group of 25 - 34 years (35.41\%), followed by $26.58 \%, 20.66 \%, 13.18 \%$ and $2.59 \%$ in the age groups of 0 - 14 years, 35 - 49 years, 15 - 24 years and above 50 


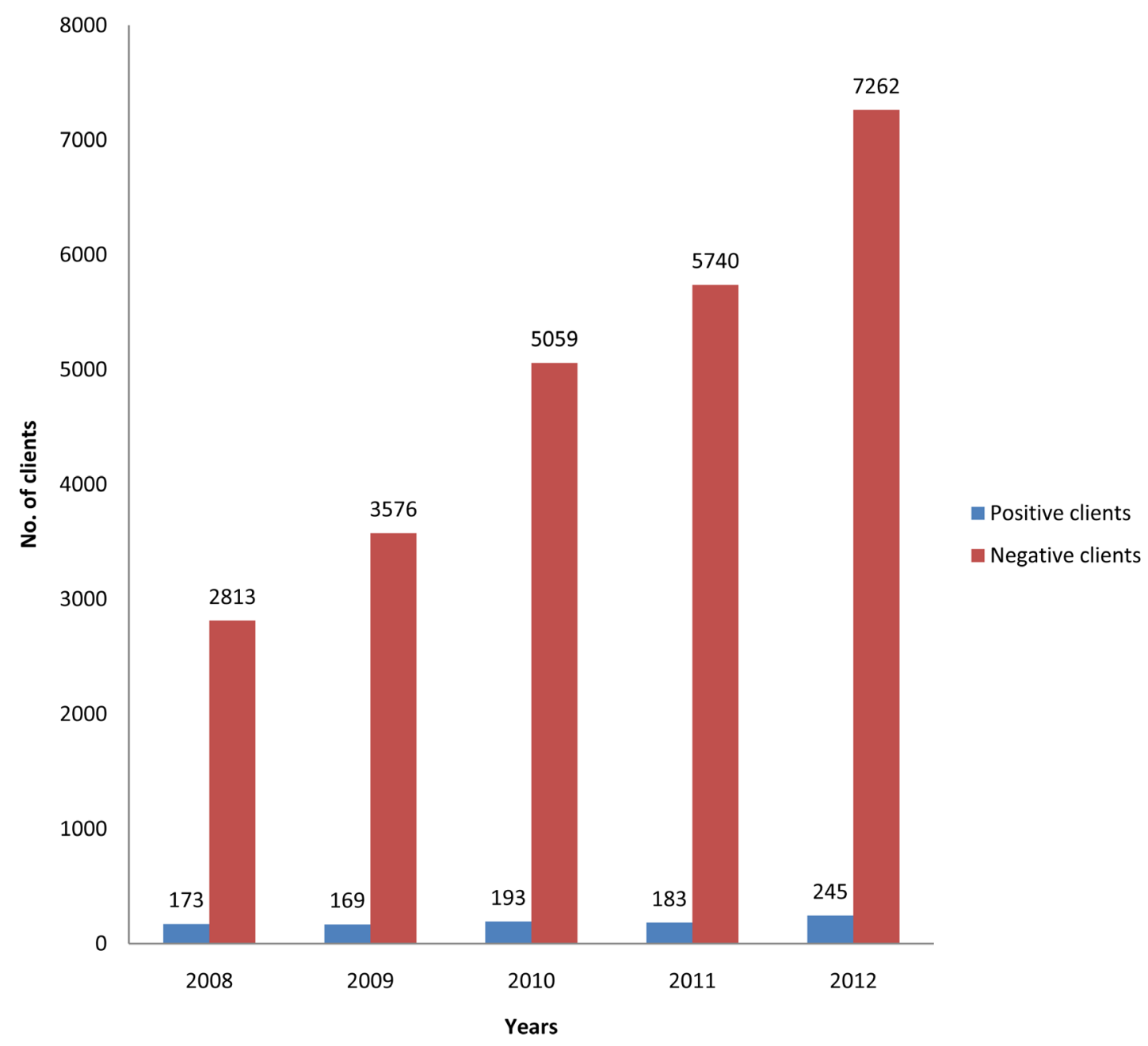

Figure 1. Seroprevalence of HIV clients.

Table 1. Prevalence of HIV from the year 2008-2012.

\begin{tabular}{|c|c|c|c|c|c|c|}
\hline Year & Total No. of clients & $\begin{array}{c}\text { Total } \\
\text { seronegative }\end{array}$ & $\begin{array}{c}\text { Total } \\
\text { seropositive }\end{array}$ & $\mathbf{M}$ & Positive clients F & TG \\
\hline 2008 & 2986 & 2813 & 173 & 122 (70.6\%) & $51(29.4 \%)$ & 0 \\
\hline 2009 & 3745 & 3576 & 169 & 101 (59.7\%) & $68(40.3 \%)$ & 0 \\
\hline 2010 & 5252 & 5059 & 193 & $122(63.2 \%)$ & $70(36.2 \%)$ & $1(0.6 \%)$ \\
\hline 2011 & 5923 & 5740 & 183 & 129 (70.5\%) & 54 (29.5\%) & 0 \\
\hline 2012 & 7507 & 7262 & 245 & 151 (61.6\%) & 93 (37.9\%) & $1(0.5 \%)$ \\
\hline Total & 25,413 & 24,450 & $963(3.78 \%)$ & $625(64.4 \%)$ & 336 (34.8\%) & $2(0.2 \%)$ \\
\hline
\end{tabular}

years of age respectively. The comparison of seropositivity in various age groups is depicted in Figure 2 and Table 2.

When the ratio of male to female clients was analyzed in these age groups highest male to female ratio 2.26:1 was observed in the age group of 35 - 49 years followed by 2.12:1 in clients above the age of 50 years. Almost similar ratio of male to female clients was observed in $0-34$ years of age group. However the ratio of male to 


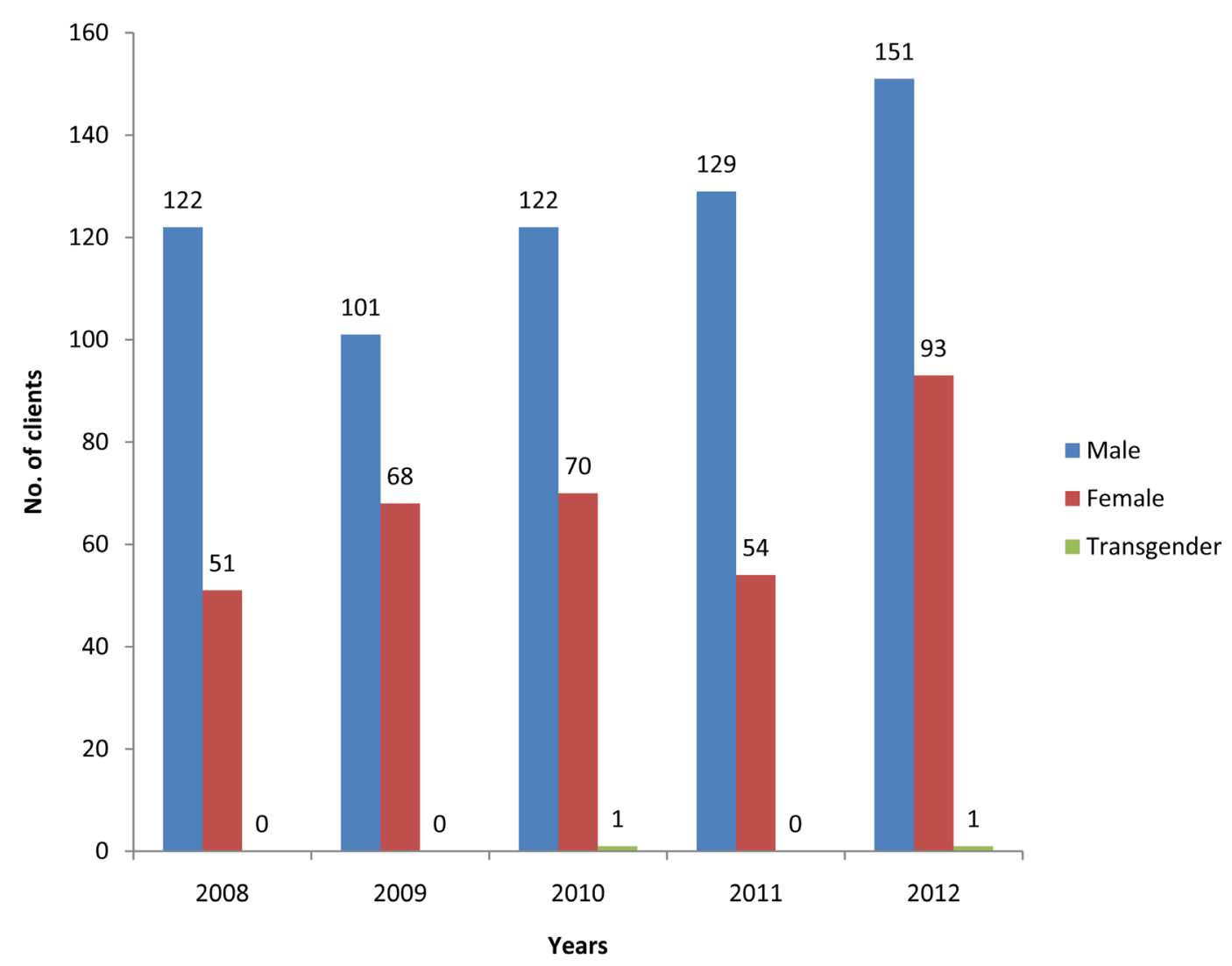

Figure 2. Gender wise distribution of seropositive clients.

Table 2. Age and sex wise distribution of the seropositive clients.

\begin{tabular}{|c|c|c|c|c|c|c|c|c|c|c|c|}
\hline \multirow{3}{*}{ Year } & \multicolumn{10}{|c|}{ Age group in years } & \multirow{3}{*}{$\begin{array}{c}\text { Ratio } \\
\text { M:F } \\
\text { year } \\
\text { wise }\end{array}$} \\
\hline & \multicolumn{2}{|c|}{$0-14$} & \multicolumn{2}{|c|}{$15-24$} & \multicolumn{2}{|c|}{$25-34$} & \multicolumn{2}{|c|}{$35-49$} & \multicolumn{2}{|c|}{$\geq 50$} & \\
\hline & $\mathbf{M}$ & $\mathbf{F}$ & M & $\mathbf{F}$ & $\mathbf{M}$ & $\mathbf{F}$ & $\mathbf{M}$ & $\mathbf{F}$ & $\mathbf{M}$ & $\mathbf{F}$ & \\
\hline 2008 & 35 & 14 & 11 & 11 & 52 & 17 & 21 & 8 & 2 & 0 & 2.39:1 \\
\hline 2009 & 25 & 21 & 13 & 16 & 38 & 16 & 24 & 13 & 1 & 1 & $1.48: 1$ \\
\hline 2010 & 38 & 21 & 11 & 13 & 34 & 26 & 20 & 13 & 5 & 2 & $1.74: 1$ \\
\hline 2011 & 36 & 14 & 18 & 9 & 49 & 23 & 20 & 10 & 3 & 0 & $2.38: 1$ \\
\hline 2012 & 31 & 21 & 10 & 15 & 51 & 35 & 53 & 17 & 6 & 5 & $1.62: 1$ \\
\hline Total & 165 & 91 & 63 & 64 & 224 & 117 & 138 & 61 & 18 & 8 & $1.78: 1$ \\
\hline$(\%)$ & $(64.4)$ & (35.6) & (49.6) & (51.4) & (65.6) & (34.3) & (69.3) & (30.6) & (68) & (32) & \\
\hline
\end{tabular}

female clients in the age group of 15 - 24 years was almost same i.e. 0.98:1 (Figure 3). Overall male to female ratio of the seropositive group over the years 2008, 2009, 2010, 2011 and 2012 was 2.39:1, 1.48:1, 1.74:1, 2.38:1 and 1.62:1 respectively (Figure 2).

Heterosexual route was the major form of transmission (70.1\%) with male to female ratio of 1.85:1 followed by the route of mother to child transmission (24.1\%), unknown reason of transmission (4.77\%). Through blood and blood products the transmission was $2.18 \%$. Least transmission was observed by homosexual route and infected needles \& syringes i.e. $0.2 \%$. The mother to child transmission was observed more in males compared to females (1.67:1) (Table 3). 


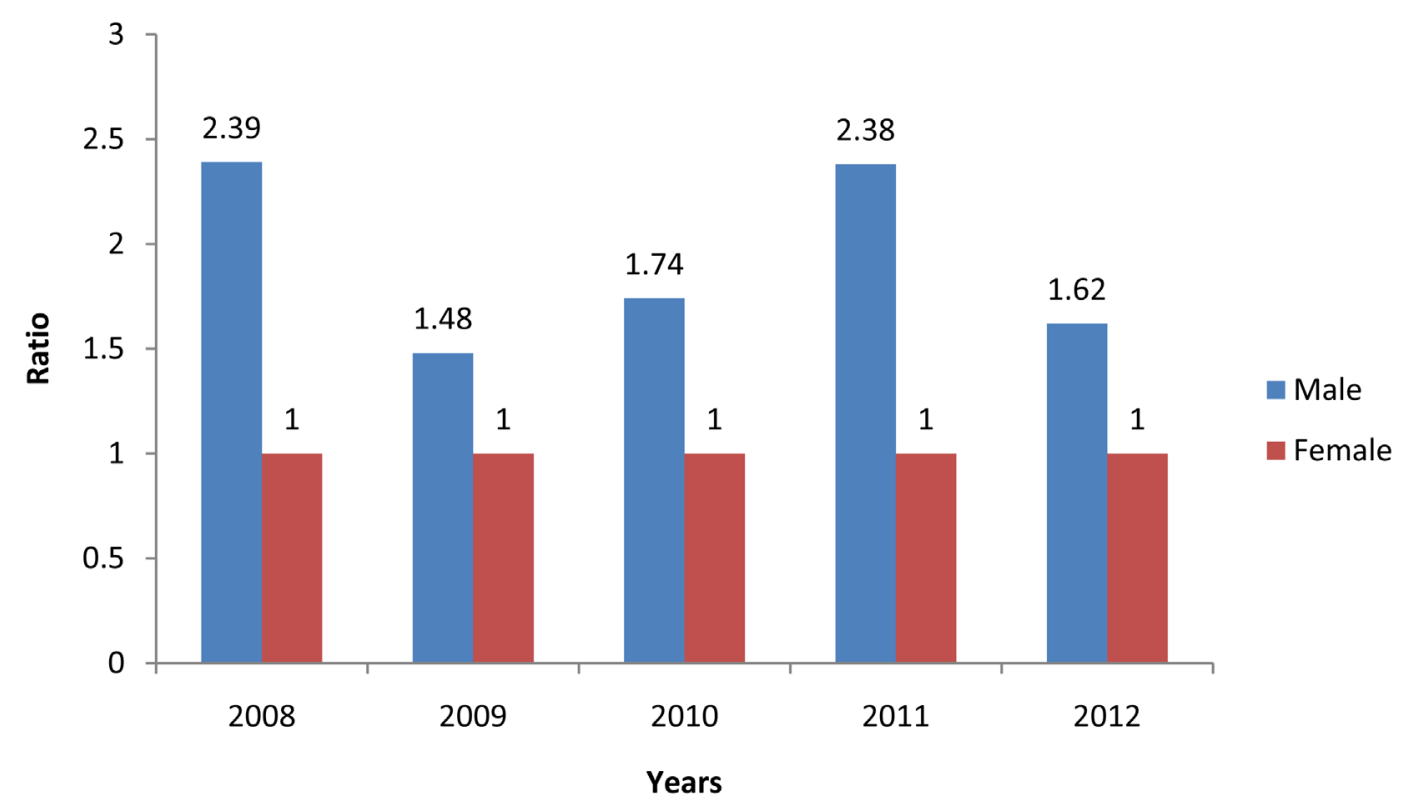

Figure 3. Ratio of male:female according to the age distribution.

Table 3. Route of transmission wise distribution of the seropositive clients.

\begin{tabular}{|c|c|c|c|c|c|c|c|c|c|c|}
\hline \multirow{2}{*}{ Year } & \multicolumn{2}{|c|}{ Heterosexual } & \multirow{2}{*}{$\begin{array}{c}\text { Homosexual } \\
\mathbf{M}\end{array}$} & \multicolumn{2}{|c|}{$\begin{array}{l}\text { Through blood } \\
\text { or blood product }\end{array}$} & \multirow{2}{*}{$\begin{array}{c}\text { Through infected } \\
\text { needles \& syringes } \\
\text { M }\end{array}$} & \multicolumn{2}{|c|}{ Mother to child } & \multicolumn{2}{|c|}{ Unknown } \\
\hline & $\mathbf{M}$ & $\mathbf{F}$ & & $\mathbf{M}$ & $\mathbf{F}$ & & $\mathbf{M}$ & $\mathbf{F}$ & $\mathbf{M}$ & $\mathbf{F}$ \\
\hline 2008 & 92 & 37 & 0 & 0 & 0 & 0 & 35 & 14 & 0 & 0 \\
\hline 2009 & 65 & 40 & 1 & 2 & 6 & 0 & 20 & 26 & 14 & 4 \\
\hline 2010 & 76 & 47 & 0 & 1 & 4 & 1 & 29 & 14 & 13 & 7 \\
\hline 2011 & 86 & 42 & 1 & 4 & 3 & 1 & 31 & 10 & 7 & 0 \\
\hline 2012 & 120 & 71 & 0 & 0 & 1 & 0 & 31 & 23 & 1 & 0 \\
\hline Total & 439 & 237 & 2 & 7 & 14 & 2 & 146 & 87 & 35 & 11 \\
\hline
\end{tabular}

In this study we observed that, 39 (6.28\%) clients were HIV-TB co-infected among the studied population in three years (2010-2012). HIV-TB co-infection was 5.2\%, 9.3\% and 4.9\% respectively in the years 2010, 2011 and 2012 (Figure 4).

\section{Discussion}

The present study has documented the prevalence and risk factors of HIV infection among a large number $(\mathrm{N}=$ 25413) of clients attending ICTC (excluding ANC clients) in a tertiary care hospital situated in central Delhi. Present study shows seropositivity of $3.78 \%$ among clients attending this ICTC. This is very high as compared to the seroprevalence among the general population (0.34\%). While Delhi is a low prevalence state and in Delhi HIV prevalence in general population is $0.25 \%$ [8], high seroprevalence in this area is because more clients in this ICTC are from High-Risk Groups (HRG) like NGO’s, MSM’s, and Transgender.

The attendees of ICTC have shown a significant increase from 2986 (in the year 2008) to 7507 (in the year 2012). There was also a significant increase in the percentage of positive female clients from 9.47\% (51/173) in the year 2008 to 37.95\% (93/245) in 2012. This may be attributed to either increased awareness about the disease; lesser stigma associated with it nowadays, expanded coverage and the availability of anti retroviral therapy (ART). The large difference in male to female positivity ratio 2.39:1, 1.48:1, 1.74:1, 2.38:1, 1.62:1 in the years 2008, 2009, 2010, 2011 and 2012 respectively shows that females are still not availing the medical facilities as 


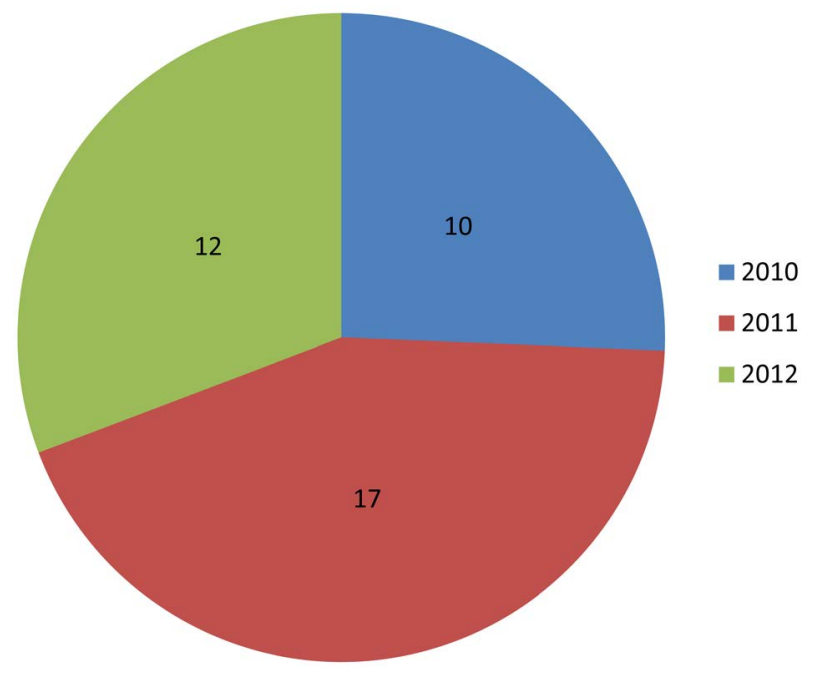

Figure 4. HIV-TB co-infection.

much as males. In our study, the positivity rate was low in females as compared to males but according to Vyas et al. [9], their six years (2002-2007) ICTC based study shows that the positivity rates were found to be higher among females. According to Madkar et al. [10], male to female ratio in HIV seropositive individuals was 3.09:1.

It is observed that in the age group ranging from 15 - 49 years, the seropositivity rate is $69.2 \%$. According to Vyas et al. [9] the positivity rate is ranging from $85.99 \%$ to $90.55 \%$ in the age group of 15 - 49 years and according to Madkar et al. [10] the prevalence of HIV infection was highest in the age group of 30 - 39 years followed by 20 - 29 years. As per our national figure, it is also observed that about $89 \%$ of the cases occurred among sexually active persons aged 20 - 49 years [11] [12].

In the present study higher seropositivity was observed in the age group of 0 - 14 years (26.58\%) with male to female ratio of 1.81:1 when compared to study done by Madkar et al. [10] (8.86\%). The significant difference was observed as Lady Hardinge Medical College (LHMC) is associated with Kalawati Saran Children Hospital (KSCH) which is the largest children hospital in Delhi. All the suspected children are referred from KSCH to ICTC, LHMC which is probably the reason for increased number of clients in this age group.

Unprotected heterosexual contact has come out to be the most common mode of transmission of HIV in the present study with the rate of $70.1 \%$ with the male and female ratio of 1.85:1. According to Vyas et al. [9] the most common mode of transmission is also the heterosexual route of transmission in Jaipur with the rate of upto 81.6\%. But in accordance with that reported by Lal et al. [11], the same rate is $84 \%$ in India.

In this study, the perinatal transmission was found to be ranging from $5.08 \%$ in the year 2008 to $5.6 \%$ in the year 2012. According to Vyas et al. [9], the same was found to be ranging from $5.6 \%$ to $12 \%$ but according to Joardar et al. [13] the rate was a little lower i.e. 2. 63\%. Mother to child transmission can occur in uterus or during breast feeding. In the present study, transmission was found to be more in male child as compared to the female child (1.67:1). This ratio is similar to the overall ratio observed in various age groups. This area needs further investigation to justify the distribution and support the observation. More studies are warranted for validation of this finding. In industrialized countries, advances in the prevention of mother to child transmission have substantially reduced the number of children who acquire HIV [14]. In India, poor access to health care system, ignorance of the masses, financial constraints and NACO policy till recently of not screening all the antenatal mothers unless the prevalence rates exceed one percent in the area may lead to increasing pediatric HIV infections in coming years [15].

Transmission through blood transfusions, once a concern in many countries, has been nearly eliminated in developed countries by the routine mandatory screening of blood donations [14]. In developing countries, transmission through the blood transfusion has yet to be eliminated, especially where HIV prevalence rates among blood donors are high and where screening of blood for HIV has not become routine [14]. India still has many paid blood donors; contaminated blood and blood products account for about $2 \%$ of HIV infections [16]. In this study, only 21 clients ( 7 male \& 14 female) gave the history of transmission through blood or blood 
products over the study period. It is the information provided by clients. It could not be established that transmission was surely through blood products.

Injection drug use (IDU) plays a critical role in the HIV epidemic in various regions, particularly in Asia and Southern Europe. According to studies in Southeast Asia, HIV prevalence among IDUs rose to $40 \%$ within 1 to 2 years after the first positive HIV test result. This was true for Manipur and in North-East India, where intravenous drug abuse is common. Delhi has a rate of 35\% IDUs with STI symptoms, but in this study only 2 cases (0.2\%) fell under this category whereas according to Vyas et al. [9], 13 cases observed from the year 2002 to 2007. Well documented HIV prevention strategies like outreach to IDUs, peer education programs and social network interventions that have reduced HIV transmission among IDUs in developed countries are now being adopted in developing countries also [14].

Tuberculosis (TB) is the most common serious opportunistic infection in HIV positive patients worldwide. After the detection and recognition of HIV in 1983, the declining curve of TB infection started to show a sudden rise during 1990s. Co-infection with HIV and TB has already been reported which is also one of the most significant global public health concerns. In the present study, the HIV-TB co-infection rate was found to be $6.28 \%$ (39/621) over the period of three years (2010-2102). Co-infection of HIV-TB was 5.2\%, 9.3\% and 4.9\% respectively in the year 2010, 2011 and 2012. According to Kamath et al. [17], HIV-TB was diagnosed in 18.9\% with higher prevalence among males at an ART in Southern India and according to Giri et al. [18], the prevalence was $17 \%$ and as per Ghiya et al. [19], the prevalence of HIV-TB co-infection was $49 \%$ in Vadodara, Gujarat which was substantially higher than that reported in previous studies. In the present study 2008 and 2009 data available was sparse. The programme was intensified from 2010 onwards.

According to the latest UNAIDS report, India managed to reduce its HIV count by a staggering 57 percent while both Bangladesh and Sri Lanka saw an increase in HIV cases by 25 percent. India is not alone though in reining the overall spread of the disease. Worldwide, the number of people newly infected continues to fall: the number of people (adults and children) acquiring HIV infection in 2011 (2.5 million) is 20 percent lower than in 2001. In 2011, 1.7 million people died from AIDS related causes worldwide. This represents a 24 percent decline in AIDS-related mortality compared with 2005 when 2.3 million deaths occurred [20].

India had responded promptly to the HIV/AIDS challenge at the initial stage itself by setting up an AIDS task force under the Indian Council of Medical Research and a National AIDS Committee headed by the Secretary, Ministry of Health and Family Welfare. In 1990, a medium term plan was launched in four states (Tamilnadu, Maharashtra, West Bengal \& Manipur) and four metropolitan cities (Mumbai, Kolkata, Chennai \& Delhi). The plan facilitates targeted IEC campaigns, establishment of surveillance system and safe blood supply [5]. The National Response to HIV/AIDS in India over the last decade has yielded encouraging outcomes in terms of prevention \& control of HIV. As the HIV testing in India is a voluntary testing i.e. not mandatory or strict for every individual in the community, it is actually a very challenging job to estimate the actual prevalence of HIV among the people who are not attending ICTC or any of the testing centres voluntarily. Taking this point in consideration, the prevalence of HIV in our study (3.78\%) among the clients attending our ICTC centre was much higher in comparison to the prevalence of HIV in adult Indian population i.e. $0.34 \%$ (0.25\% - 0.43\%) [10].

\section{Conclusions}

ICTCs are important for prevention, detection and care of HIV infection. The ICTC-LHMC caters to a huge population being located in the heart of Delhi. ICTC-LHMC gives services like pre-test counseling, testing of HIV, post-test counselling, communication with ART centre for treatment of positive patients. With these services, this centre is taking responsibilities in terms of testing HIV infections, helping in behavioral modifications of high-risk people through counseling as well as care and support of the people living with HIV.

This study reports for the first time the seroprevalence of HIV among the clients attending ICTC in Lady Hardinge Medical College, New Delhi. In this study, prevalence of HIV infection in clients attending ICTC is $3.78 \%$. There is a male preponderance over female from sexually active age group of 25 - 34 years of age. Hence we should focus on this age group especially male group for the prevalence of high rate of HIV transmission. This would help in the development of the appropriate policies and strategies to reduce the spread of HIV infection in India. All these findings suggest the need for the scaling up of focused prevention efforts among these groups. Perinatal transmission was observed more in the male child (1.67:1). This needs to be proven by undertaking further studies. 


\section{Limitation of the Study}

All clients interviewed in pre-counseling session attended the ICTC-LHMC for HIV screening on a voluntary basis or referred basis. The interview schedule included sensitive data like the history of risk behavior and history of HIV in the family or the partner. It is possible that the data reported here could be biased due to recall error or social stigma faced by the patients in the community.

\section{Acknowledgements}

To all staff working at Centre for HIV Testing (CHT), Department of Microbiology, Lady Hardinge Medical College, New Delhi.

\section{Conflict of Interest}

There is no conflict of interest regarding the publication of this paper.

\section{Source of Funding}

National AIDS Control Organization (NACO)/Delhi State AIDS Control Society (DSACS).

\section{References}

[1] Narain, J.P., Jha, A., Lal, S. and Salunke, S. (1994) Risk Factors for HIV Transmission in India. AIDS, 8, S77-S82.

[2] UNAIDS (2012) Report on the Global AIDS Epidemic.

[3] UNAIDS (2012) World AIDS Day Report: Results.

[4] UNAIDS (2011) AIDS at 30: Nations at the Crossroads.

[5] NACO Annual Report 2011-12.

[6] Moses, S., Blanchard, J.F., Kang, H., et al. (2006) AIDS in South Asia: Understanding and Responding to a Heterogeneous Epidemic. The World Bank, Washington DC, 7-19. http://dx.doi.org/10.1596/978-0-8213-6757-5

[7] NACO Guidelines, March 2007.

[8] HIV/AIDS Scenario in Delhi. http://delhi.gov.in/wps/wcm/connect/doit/Delhi+Govt/Delhi+Home

[9] Vyas, N., Hooja, S., Sinha, P., Mathur, A., Singhal, A. and Vyas, L. (2009) Prevalence of HIV/AIDS and Prediction of Future Trends in North-West Region of India: A Six Year ICTC Based Study. Indian Journal of Community Medicine, 34, 212-217. http://dx.doi.org/10.4103/0970-0218.55286

[10] Madkar, S.S., Nilekar, S.L. and Vankudre, A.J. (2011) Prevalence of HIV Infection among Persons Attending Integrated Counseling and Testing Centre, Ambajogai. National Journal of Community Medicine, 2, 213-215.

[11] Lal, S. (2003) Surveillance of HIV/AIDS in India (Editorial). Indian Journal of Community Medicine, 27, 3-9.

[12] Park, K. (2002) Park’s Text Book of Preventive and Social Medicine. 17th Edition, M/s Banarsidas Bhanot, Jabalpur, 259-267, 314-316.

[13] Joardar, G.K., Sarkar, A., Chatterjee, C., et al. (2006) Profiles of Attendees in the Voluntary Counseling and Testing Center of North Bengal Medical College in Darjeeling District of West Bengal. Indian Journal of Community Medicine, 31, 43-46.

[14] Gayle, H.D. and Hill, G.I. (2001) Global Impact of Human Immunodeficiency Virus and AIDS. Clinical Microbiology Reviews, 14, 327-335. http://dx.doi.org/10.1128/CMR.14.2.327-335.2001

[15] Sehgal, S., Datta, U., Arora, S., et al. (2008) Time Trends of Pediatric HIV Infection in North India. Journal of the Indian Medical Association, 106, 162-164.

[16] Steinbrook, R. (2007) HIV in India-A Complex Epidemic. The New England Journal of Medicine, 356, $1089-1093$. http://dx.doi.org/10.1056/NEJMp078009

[17] Kamath, R., Sharma, V., Pattanshetty, S., Hegde, M.B. and Chandrasekaran, V. (2013) HIV-TB Coinfection: ClinicoEpidemiological Determinants at an Antiretroviral Therapy Centre in Southern India. Lung India, 30, 302-306. http://dx.doi.org/10.4103/0970-2113.120605

[18] Giri, P.A., Deshpande, J.D. and Phalke, D.B. (2013) Prevalence of Pulmonary Tuberculosis among HIV Positive Patients Attending Antiretroviral Therapy Clinic. North American Journal of Medical Sciences, 5, 367-370. http://dx.doi.org/10.4103/1947-2714.114169 
[19] Ghiya, R., Naik, E., Casanas, B., Izurieta, R. and Marfatia, Y. (2009) Clinico-Epidemiological Profile of HIV/TB Coinfected Patients in Vadodara, Gujarat. Indian Journal of Sexually Transmitted Diseases, 30, 10-15. http://dx.doi.org/10.4103/0253-7184.55472

[20] India Winning Battle against HIV/AIDS, December 2012.

\section{Abbreviations}

AIDS: Acquired Immune Deficiency Syndrome

ART: Anti-Retro Viral Therapy

DSACS: Delhi State AIDS Control Society

HRG: High-Risk Group

HIV: Human Immunodeficiency Virus

IEC: Information Education and Communication

IDUs: Intravenous Drug Users

ICTC: Integrated Counseling and Testing Centre

LHMC: Lady Hardinge Medical College

MSM: Man Having Sex with Man

NACO: National AIDS Control Organization

NACP: National AIDS Control Programme

NGO: Non Government Organisation

TB: Tuberculosis

TG: Transgender

UNAIDS: United Nations Programme on HIV and AIDS 
Scientific Research Publishing (SCIRP) is one of the largest Open Access journal publishers. It is currently publishing more than 200 open access, online, peer-reviewed journals covering a wide range of academic disciplines. SCIRP serves the worldwide academic communities and contributes to the progress and application of science with its publication.

Other selected journals from SCIRP are listed as below. Submit your manuscript to us via either submit@scirp.org or Online Submission Portal.
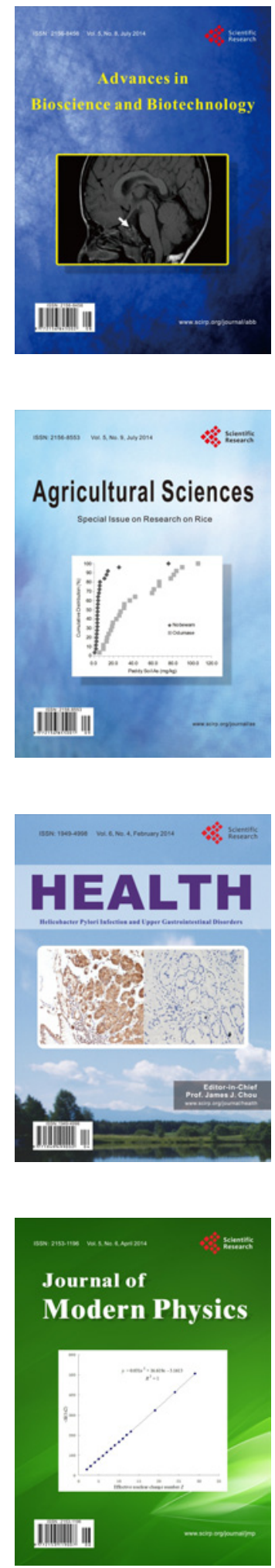
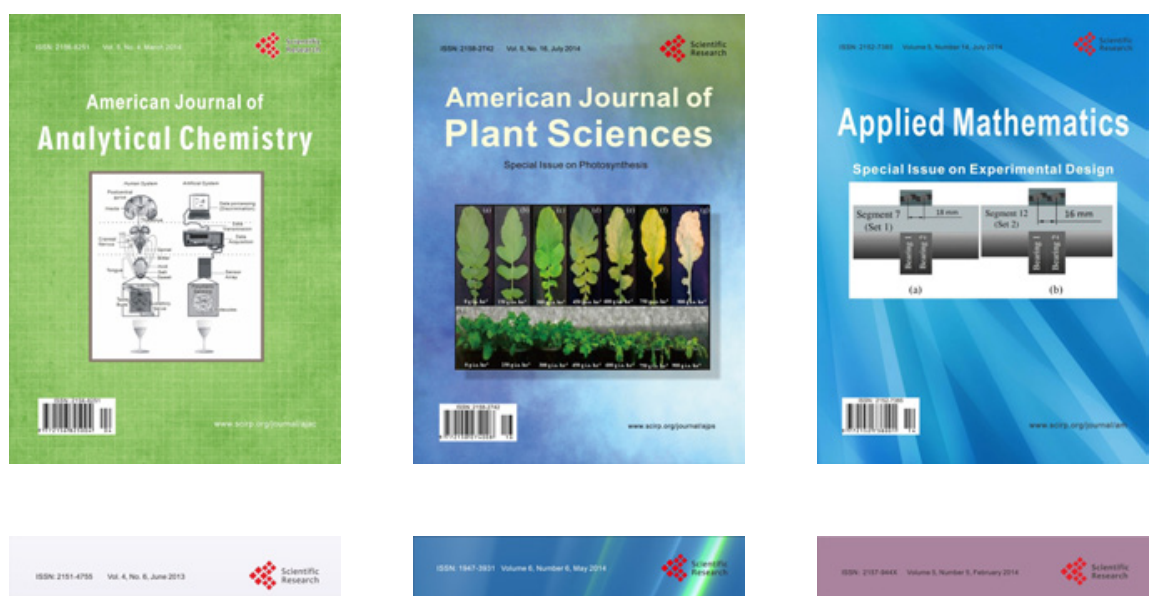

Creative Education
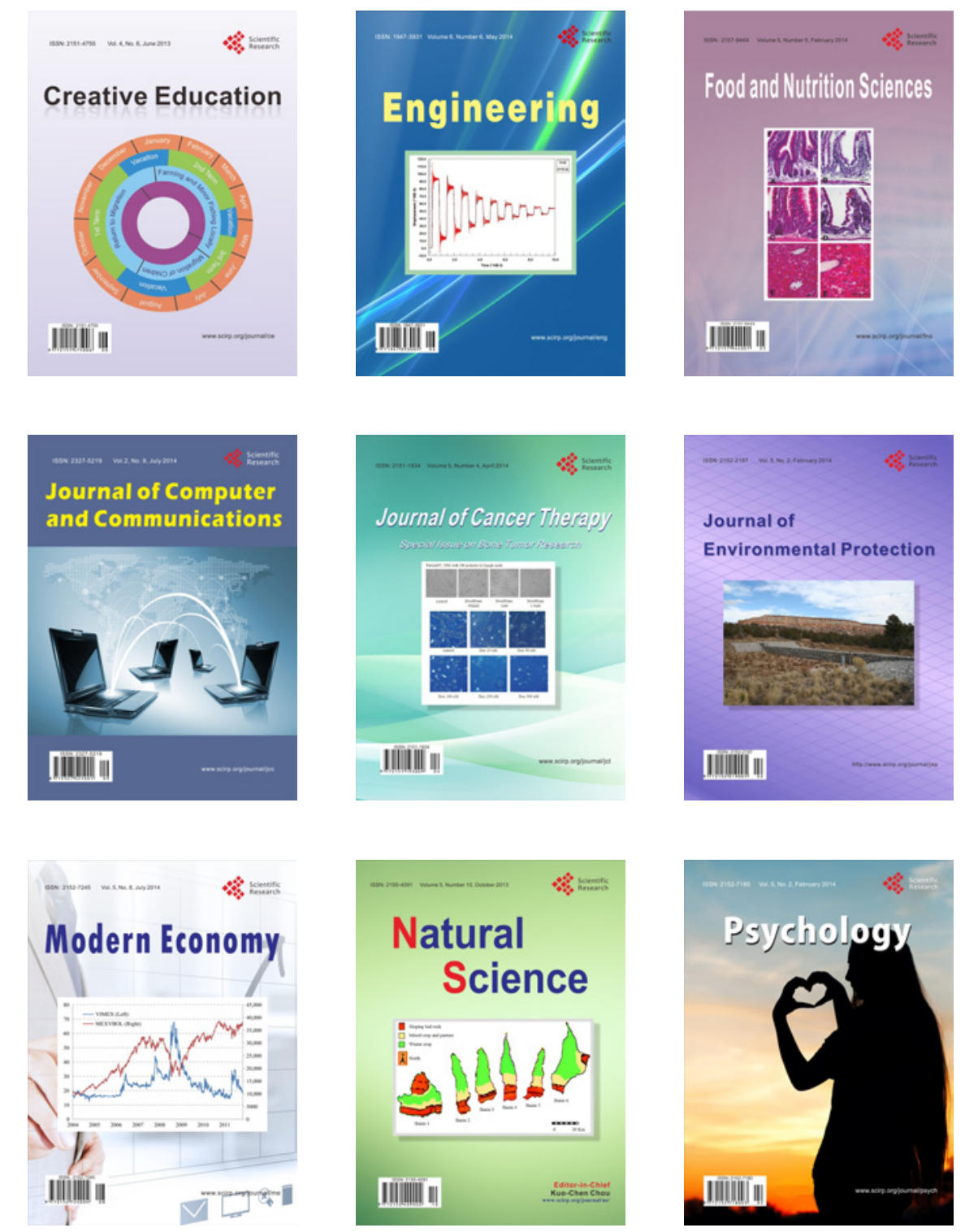